\title{
Which measure of quality of life performs best in older age? A comparison of the OPOOL, CASP-19 and WHOQOL-OLD
}

\author{
Ann Bowling, ${ }^{1}$ Paul Stenner ${ }^{2}$
}

- Additional informations are published online only. To view these files please visit the journal online (http://jech.bmj.com).

${ }^{1}$ Faculty of Health and Social Care Sciences, Kingston University \& St George's, University of London, UK ${ }^{2}$ School of Applied Social Sciences, University of Brighton, Sussex, UK

\section{Correspondence to} Professor Ann Bowling, Faculty of Health and Social Care Sciences, Kingston University \& St George's, University of London, Cranmer Terrace, London, SW17 ORE, UK; a.bowling@sgul.kingston.ac.uk

This work was completed whilst the corresponding author was at Department of Primary Care and Population Sciences, University College London, Hampstead Campus, London, UK

Accepted 30 November 2009 Published Online First 18 August 2010

\section{(2) UNLOCK:}

This paper is freely available online under the BMJ Journals unlocked scheme, see http:// jech.bmj.com/site/about/ unlocked.xhtml

\begin{abstract}
Background Most measures of quality of life (QoL) are based on 'expert' opinions. This study describes a new measure of QoL in older age, the Older People's QoL Questionnaire (OPOOL), which is unique in being derived from the views of lay people, cross-checked against theoretical models for assessment of comprehensiveness. Its performance was assessed cross-sectionally and longitudinally. It was compared with two existing OoL measures in the cross-sectional studies in order to identify the optimal measure for use with older populations.

Methods Data were taken from three surveys of older people living at home in Britain in 2007-2008: one population survey of people aged $65+$, one focused enumeration survey of ethnically diverse older people aged $65+$, one follow-up of a population survey of people aged $65+$ at baseline in 1999/2000. Measures were 0oL (using OPOOL, Control, Autonomy, Satisfaction, Pleasure - 19 items (CASP-19), World Health Organization Quality of Life questionnaire - version for older people (WHOQOL-OLD)), health, social and socioeconomic circumstances. The CASP-19 and WHOOOL-OLD were not administered to the longitudinal sample in order to reduce respondent burden.
\end{abstract}

Results Psychometric tests were applied to each OoL measure. The OPOOL, CASP-19 and WHOQOL-OLD performed well with the cross-sectional samples; however, only the OPOOL met criteria for internal consistency in the Ethnibus samples.

Conclusion The OPOOL is of potential value in the outcome assessment of health and social interventions, which can have a multidimensional impact on people's lives. Further research is needed to examine whether differences by ethnicity reflect real differences in OoL, methodological issues, variations in expectations or cultural differences in reporting.

\section{BACKGROUND}

Governments across the developed world are concerned with enabling older people to maintain their active contribution to society, and thereby their quality of life (QoL). ${ }^{1}$ OoL has become a commonly used end point in the evaluation of multisector public policy, including health, social, community and environmental policy actions.

For policy outcomes to be measured with any validity, measures of GoL need to have social, as well as policy, relevance, to be meaningful to people's lives, and to be carefully conceptualised and constructed.

Lawton ${ }^{2-6}$ developed a popularly cited quadripartite concept of QoL, proposing that the 'good life' (QoL) may be represented by behavioural and social competence (health, cognition, time use, social behaviour), perceptions of GoL (subjective evaluation of each domain of life), psychological well-being (mental health, cognitive judgements of life satisfaction, positive-negative emotions) and the external, objective, physical environment (housing, economic indicators). However, there is no consensus about its conceptual definition or measurement, ${ }^{7}$ and most investigators have based their concepts on expert opinions rather than the perspectives of lay people. This has the consequence that there are few empirical data on the extent to which the items included in measurement scales have any relevance to people. Thus, it is increasingly important to develop a multidimensional model and measure of quality of life, for use in descriptive and evaluative multisector policy research, which reflects the views of the population concerned, with crosssectional and longitudinal applicability. Elicitation of people's own views of QoL in this process is particularly important because QoL is a subjective concept.

What are older people's views of QoL? Survey and qualitative research with people aged $65+$, living at home in Britain, reported that the central planks of QoL emphasised by respondents were psychological well-being and positive outlook, having health and functioning, social relationships, leisure activities, neighbourhood resources, adequate financial circumstances and independence. ${ }^{7-10}$ This research led to the development of the Older People's Quality of Life Questionnaire (OPOOL), which is unique in being derived from the views of a representative sample of older people, cross-checked against theoretical models for assessment comprehensiveness.

\section{METHODS}

The aim here is to compare the psychometric properties of the OPQOL, with the CASP-19 and WHOQOL-OLD among people 65+ participating in three national surveys of older people living at home in Britain. Two of these three surveys were cross-sectional, and the third was longitudinal (see supplementary Appendix 1):

1. Ethnibus survey of people aged $65+$ responding to two waves of the national Ethni Surveys (http://www.ethnicfocus.com) in 2008. This is a rolling face-to-face interview survey with adults aged 16+, living at home, based on focused enumeration, stratified random sampling of postcodes in Britain, and statistically robust sampling of people in common ethnic minority groups in Britain; the response rate was 70\% $(n=400)$.

2. ONS survey of people aged $65+$ responding to two waves of the Office for National Statistics 
(ONS) national Omnibus Survey (http://www.statistics.gov. $\mathrm{uk}$ ) in 2008. This is a rolling face-to-face interview survey with adults aged $16+$, living at home, based on a stratified random sample of postcodes across Britain; the response rate was $61 \%(n=589)$.

3. QoL follow-up survey in 2007-2008, of people living at home in Britain, aged $65+$ at baseline, who had responded to four ONS national Omnibus interview surveys. These were based on stratified random samples of postcodes across Britain during 1999/2000; response was $77 \%(n=999)$ at baseline and $58 \%$ among survivors $(n=287)$ at $2007-2008$ follow-up. The QoL follow-up survey is included here as the longitudinal design provided the opportunity to test the causal model of the OPQOL, as well as a willing sample for test-retest reliability assessment.

\section{Measures}

The OPQOL was administered in all three surveys. Prior to administration in the surveys reported here, the items in the OPQOL were pretested with 179 older people and three focus groups, reduced to 32 -item and 35 -item versions, and statistical tests of reliability and validity were applied. The CASP- $19^{11}$ and the WHOQOL-OLD ${ }^{12} 13$ were administered in the two face-toface interview surveys only; it would have been too cognitively burdensome to have included all three scales in the postal, selfadministration mode. Supplementary Appendix 2 displays the OPQOL, summarises its development and briefly summarises the CASP-19 and WHOQOL-OLD.

Independent self-ratings of global QoL, and of its domains, were included in the questionnaire in order to distinguish between the constituents of, and influences on, QoL. ${ }^{14}$ Also included were standard sociodemographic items, self-rated active ageing, items measuring health and psychosocial circumstances. ${ }^{7}$ Ethnic status was measured using a standard item about ethnic identity in the UK. This would not necessarily be applicable to populations in other countries, because it reflects close connections between New Commonwealth countries and ethnic minority groups in the UK. ${ }^{15}$

\section{Statistical analysis}

Descriptive analyses included frequencies, $\chi^{2}$ tests, and Spearman's $r$ correlations. Tests of scale reliability were applied in order to assess the extent to which scale items measure the same construct, with freedom from random error (internal consistency). Reliability tests applied to the $\mathrm{QoL}$ scales included Cronbach's $\alpha$ test of homogeneity. This is the strength of the association between each scale item and the full scale, item-item and item-total correlations. Test-retest reliability of the stability of the newly developed OPQOL was assessed by mailing a second copy of the questionnaire to a random subsample of 50 follow-up QoL survey respondents, 4 weeks after return of the first questionnaire (response rate: 76\%/38).

Criterion (concurrent) validity is the independent corroboration that the scale is measuring what it intends to measure. This can only be measured by proxy with subjective measures, as there is no gold standard. Proxy variables used here included independent self-ratings of QoL overall and of QoL domains (health, social relationships, independence/control over life/ freedom, home and neighbourhood, psychological/emotional well-being, financial circumstances, social and leisure activities). Construct (convergent and discriminant) validity requires corroboration that scales measure the underlying construct they purport to measure. This was tested by assessing Spearman's $r$ correlations between the QoL scales and similar variables (for convergent validity that the scale should correlate with similar or hypothesised variables) and dissimilar variables (for discriminant validity that there should be low correlations between scales and variables not expected to be associated).

Multiple regression was used to assess validity further by examining the ability of theoretically relevant variables to predict total QoL scores. A hierarchical approach was used, with independent variables entered in their theoretical order of importance. Statistical significance was set at $p<0.05$. The variables entered did not correlate by more than 0.732 ; tests for multicollinearity were satisfied. Sociodemographic variables were entered to adjust for their effects.

\section{RESULTS}

\section{Characteristics of samples}

Just over half of each sample comprised women (52\%/207 Ethnibus, 55\%/324 ONS, 54\%/154 QoL follow-up). Whereas most Ethnibus respondents were aged $65<75$ (91\%/363), just over half of ONS Omnibus (55\%/326), and less than a fifth of QoL follow-up respondents $(17 \% / 47)$, were aged $65<75$. Thirtyeight per cent (152) of the Ethnibus sample were Indian, 29\% (117) were Pakistani, 22\% (86) were Black Caribbean and 11\% (45) were Chinese. Most, 94\% (555) of the ONS Omnibus sample were white British; all OoL follow-up respondents were white British. In reflection of their younger age, more of the Ethnibus than other respondents were married or cohabiting (58\%/230, 49\%/285, 49\%/138 respectively). Fewer Ethnibus than other respondents were home-owners (532\%/208, 73\%/ $429,85 \% / 239$ respectively) and fewer lived alone (5\%/19, 48\%/ $286,49 \% / 137$ respectively) (All differences were statistically significant at least at $\mathrm{p}<0.01$.) For detailed characteristics of the samples, see supplementary table 1 .

\section{Distributions of samples on $\mathrm{QoL}$ scales}

Few, 12\%/70, of the ONS Omnibus sample, compared with more, $45 \% / 113$ of the older QoL follow-up sample, and 73\%/290 of the Ethnibus sample were in the lowest two OPQOL categories (<119), indicating worse QoL (see supplementary table 2).

The Ethnibus and ONS cross-sectional samples only were administered the CASP-19 and WHOQOL-OLD. Consistent with the OPQOL findings, 23\%/94 of Ethnibus respondents were in the worst two CASP-19 categories $(<29)$, compared with $8 \% / 43$ of ONS respondents; $25 \% / 100$ of the Ethnibus sample fell in the worst two WHOQOL-OLD categories, compared with 15\%/80 of the ONS respondents (see supplementary tables 3 and 4).

Further analyses by total QoL scores and ethnicity in the Ethnibus sample showed that 58\% (26) of Chinese people scored a good OoL with the OPQOL, compared with 28\% (33) of Pakistani, 20\% (31) of Indian and 23\% (31) of Black Caribbean people ( $\chi^{2}$ test $28.064,2$ degrees of freedom, $p<0.001$ ) (caution: smaller numbers). The CASP-19 and WHOQOL-OLD total scores showed no differences by ethnicity. Differences by ethnicity were not analysed in the other samples due to their low numbers in ethnic minority groups.

\section{Reliability}

The reliability criterion for item-total correlations (the correlation of the item with the scale total with that item omitted) is that the item should correlate with the total scale by at least 0.20. With three exceptions, the 35 full OPQOL items met this criterion for all three samples (the exceptions were in the Ethnibus sample with items 10, 12 and 32; but as Cronbach's $\alpha$ was not improved by their removal, and they performed well in validity tests, they were retained). Six of the 19 CASP items 
failed to meet this criterion (Ethnibus: items 1, 2, 5, 17, 18; ONS: item 6). Fourteen of the 24 WHOQOL-OLD items failed this criterion in the Ethnibus sample only. As expected, all items correlated more highly with similar, than dissimilar, items in the scales.

Cronbach's $\alpha$ for the OPQOL in all three samples satisfied the $0.70<0.90$ threshold for internal consistency: $\alpha 0.748$ (Ethnibus survey), $\alpha 0.876$ (ONS Omnibus survey), a 0.901 (QoL followup survey). The CASP-19 and the WHOQOL-OLD satisfied the threshold for Cronbach's $\alpha$ in the ONS sample ( $\alpha 0.866$ and $\alpha 0.849$ respectively), but neither met this in Ethnibus ( $\alpha 0.553$ and $\alpha 0.415$ respectively) (see earlier, neither were administered in the QoL follow-up sample).

The 4 week test-retest correlations, assessed among QoL follow-up survey respondents, ranged from moderate to high (r 0.403-0.782). Lower correlations were explained by reported life changes in the intervening month, demonstrating the difficulties of test-retest exercises in older populations. Respondents' comments at follow-up about life changes in the last 4 weeks illustrate this:

'About 4 days ago the plaster was taken off my left hand so now I can go on buses again - my only means of regular transport apart from volunteer drivers, a few friends and taxis. Anyway it means I am free';

"My husband of nearly 60 years was told he has lung cancer so it has changed very much how I feel. We are trying to be as normal as possible but it's very hard';

'My daughter and her young son have now left our home and acquired her own house. We miss them a lot';

'My husband has just come home after spending another 2 weeks in hospital (suspected heart attack)'.

\section{Validity}

In order to test the criterion (also known as concurrent) validity of the GoL scales, all respondents were asked to rate the 'OoL of their lives overall' and by area of life ('QoL domain'), using fivepoint scales from 'Very good' to 'Very bad'. The criterion validity of all three QoL scales was indicated by their moderate to strong, significant correlations with global self-rated QoL: the Spearman's r correlations for the OPQOL by self-rated QoL overall in each sample were Ethnibus -0.347, ONS -0.602 and QoL follow-up -0.659. For the CASP, in the two cross-sectional samples, they were Ethnibus -0.273 , ONS -0.577 , and for the WHOQOL-OLD, in the two cross-sectional samples, they were Ethnibus -0.128 and ONS -0.466. All correlations were significant at least at $p<0.01$, with the exception of WHOQOLOLD in the Ethnibus sample which was $p<0.05$. (Minus signs simply reflect opposite coding directions).

The validity of the OPQOL was further supported by significant correlations between its subscales and the independent QoL domain ratings, in theoretically expected, similar directions $^{7}$ (eg, OPQOL health and functioning subscale correlated with self-rated health: Spearman's $r$ Ethnibus $-0.122(p<0.05)$, ONS Omnibus $-0.679(p<0.01)$ and QoL follow-up -0.713 $(p<0.01)$. There were no significant correlations with dissimilar pairs (eg, health and religion), again as expected.

The CASP-19 Control and Autonomy subscales and the WHOQOL-OLD Autonomy subscale also correlated significantly, as expected in similar directions, with self-rated independence, control over life and freedom in the ONS sample ( $r-0.472$, $\mathrm{p}<0.01 ; \mathrm{r}-0.466, \mathrm{p}<0.01$ respectively), but not in the Ethnibus sample. The WHOQOL-OLD Sensory Abilities subscale correlated significantly, again as expected, with self-rated health in the ONS ( $\mathrm{r}-0.322, \mathrm{p}<0.01)$, but not the Ethnibus sample. The WHOQOL-OLD Intimacy subscale correlated significantly, also as expected, with the social relationships domain in the ONS sample $(r-0.330, p<0.01)$, but not in the Ethnibus sample.

Table 1 Multiple regression of predictors of OPOOL: OoL follow-up sample (final model)

\begin{tabular}{lll}
\hline $\begin{array}{l}\text { Independent predictor } \\
\text { variables }\end{array}$ & $\begin{array}{l}\text { Unstandardised B } \\
\text { Standardised } \boldsymbol{\beta}\end{array}$ & $\begin{array}{l}\mathbf{9 5 \%} \mathbf{C l} \text { (Two-tail } \\
\mathbf{p} \text { Value }\end{array}$ \\
\hline Block 1 & & \\
Self-rated active ageing & -2.637 & -4.071 to -1.203 \\
& -0.184 & $\begin{array}{l}(-3.626) \\
\end{array}$ \\
& & 0.0001
\end{tabular}

Block 2

OoL domain self-ratings QOL: health

$\begin{array}{ll}-1.965 & -3.759 \text { to }-0.172 \\ -0.122 & (-2.162) \\ & 0.032 \\ -1.341 & -2.988 \text { to } 0.306 \\ -0.080 & (-1.606) \\ & 0.110 \mathrm{NS} \\ -1.669 & -3.194 \text { to }-0.144(-2.158) \\ -0.106 & 0.032 \\ -2.108 & -3.660 \text { to }-0.556 \\ -0.106 & (-2.679) \\ & 0.008 \\ -3.258 & -4.768 \text { to }-1.749(-4.257) \\ -0.193 & 0.0001 \\ -5.223 & -6.669 \text { to }-3.777 \\ -0.273 & (-7.124) \\ & 0.0001 \\ -0.681 & -2.320 \text { to } 0.957 \\ -0.043 & (-0.820) \\ & 0.413 \text { NS } \\ & \\ 1.108 & 0.375 \text { to } 1.842 \\ 0.150 & (2.981) \\ & 0.003 \\ 0.132 & -0.032 \text { to } 0.297(1.586) \\ 0.060 & 0.114 \text { NS }\end{array}$

OoL: social relationships

QoL: independence, control over life, freedom

OoL: home and

neighbourhood

QoL: psychological and emotional well-being

OoL: financial circumstances

QoL: leisure and social activities

Block 3

Total number of different social activities done in last month (out of listed eight)

Total number of relatives,

friends, neighbours who

would help with practical

tasks

Block 4

Self-rated health status, compared to others of same age

ADL total score (sum of ability to: walk 400 yards, do heavy housework, shop/carry heavy bags, steps/stairs)

Block 5

Age

$-0.562$

$-0.041$

-2.141 to 1.018

$(-0.701)$

0.484 NS

0.238

-0.166 to 0.642

(1.163)

0.246 NS

0.008

0.004

-0.157 to 0.173

(0.095)

$0.925 \mathrm{NS}$

Sex

3.303

1.279 to 5.328

(3.219)

0.002

Marital status $\quad 0.75$

-0.250 to 1.768

(1.484)

$0.140 \mathrm{NS}$

Housing tenure

$-0.797$

-1.831 to 0.237

$(-1.520)$

Constant

153.985

$\mathrm{R}^{2}$

0.791

Adjusted $\mathrm{R}^{2}$

0.774

Anova F statistic; $\mathrm{p}$ value

45.794; 0.0001 
Table 2 Multiple regression of predictors of OPQOL: ONS Omnibus and Ethnibus samples (final models)

\begin{tabular}{|c|c|c|c|c|}
\hline \multirow[b]{2}{*}{$\begin{array}{l}\text { Independent predictor } \\
\text { variables }\end{array}$} & \multicolumn{2}{|l|}{ ONS Omnibus: } & \multicolumn{2}{|l|}{ Ethnibus: } \\
\hline & $\begin{array}{l}\text { Unstandardised B } \\
\text { Standardised beta }\end{array}$ & $\begin{array}{l}\text { 95\% Cl (2-tailed t-test) } \\
\text { p Value }\end{array}$ & $\begin{array}{l}\text { Unstandardised B } \\
\text { Standardised beta }\end{array}$ & $\begin{array}{l}\text { 95\% CI (2-tailed t-test) } \\
\text { p Value }\end{array}$ \\
\hline \multicolumn{5}{|l|}{ Block 1} \\
\hline Self-rated active ageing & $\begin{array}{l}-1.515 \\
-0.103\end{array}$ & $\begin{array}{l}-2.507 \text { to }-0.523 \\
(-3.000) \\
0.003\end{array}$ & $\begin{array}{l}-1.652 \\
-0.167\end{array}$ & $\begin{array}{l}-2.464 \text { to } 0.839 \\
(-3.998) \\
0.0001\end{array}$ \\
\hline \multicolumn{5}{|l|}{ Block 2} \\
\hline \multicolumn{5}{|l|}{ QoL domain self-ratings } \\
\hline QOL: health & $\begin{array}{l}-1.531 \\
-0.104\end{array}$ & $\begin{array}{l}-2.756 \text { to }-0.307 \\
(-2.457) \\
0.014\end{array}$ & $\begin{array}{l}-1.044 \\
-0.085\end{array}$ & $\begin{array}{l}-1.980 \text { to }-0.109 \\
(-2.194) \\
0.029\end{array}$ \\
\hline OoL social relationships & $\begin{array}{l}-1.503 \\
-0.097\end{array}$ & $\begin{array}{l}-2.577 \text { to }-0.430 \\
(-2.751) \\
0.006\end{array}$ & $\begin{array}{l}-0.213 \\
-0.017\end{array}$ & $\begin{array}{l}-1.165 \text { to } 0.739 \\
(-0.439) \\
0.661 \mathrm{NS}\end{array}$ \\
\hline $\begin{array}{l}\text { QoL: independence, control } \\
\text { over life, freedom }\end{array}$ & $\begin{array}{l}-2.081 \\
-0.133\end{array}$ & $\begin{array}{l}-3.231 \text { to }-0.931 \\
(-3.556) \\
0.0001\end{array}$ & $\begin{array}{l}-0.678 \\
-0.055\end{array}$ & $\begin{array}{l}-1.639 \text { to } 0.284 \\
(-1.386) \\
0.167 \mathrm{NS}\end{array}$ \\
\hline $\begin{array}{l}\text { QoL: home and } \\
\text { neighbourhood }\end{array}$ & $\begin{array}{l}-0.730 \\
-0.040\end{array}$ & $\begin{array}{l}-1.912 \text { to } 0.451 \\
(-1.214) \\
0.225 \mathrm{~ns}\end{array}$ & $\begin{array}{l}-3.013 \\
-0.245\end{array}$ & $\begin{array}{l}-4.022 \text { to }-2.004 \\
(-5.870) \\
0.0001\end{array}$ \\
\hline $\begin{array}{l}\text { QoL: psychological and } \\
\text { emotional well-being }\end{array}$ & $\begin{array}{l}-1.424 \\
-0.084\end{array}$ & $\begin{array}{l}-2.611 \text { to }-0.237 \\
(-2.356) \\
0.019\end{array}$ & $\begin{array}{l}-2.033 \\
-0.161\end{array}$ & $\begin{array}{l}-3.078 \text { to }-0.987 \\
(-3.821) \\
0.0001\end{array}$ \\
\hline OoL: financial circumstances & $\begin{array}{l}-3.362 \\
-0.207\end{array}$ & $\begin{array}{l}-4.366 \text { to }-2.358 \\
(-6.577) \\
0.0001\end{array}$ & $\begin{array}{l}-1.952 \\
-0.158\end{array}$ & $\begin{array}{l}-2.887 \text { to }-0.016 \\
(-4.103) \\
0.0001\end{array}$ \\
\hline $\begin{array}{l}\text { QoL: leisure and social } \\
\text { activities }\end{array}$ & $\begin{array}{l}-2.047 \\
-0.146\end{array}$ & $\begin{array}{l}-3.118 \text { to }-0.977 \\
(-3.757) \\
0.0001\end{array}$ & $\begin{array}{l}-2.184 \\
-0.191\end{array}$ & $\begin{array}{l}-3.093 \text { to }-1.275 \\
(-4.723) \\
0.0001\end{array}$ \\
\hline \multicolumn{5}{|l|}{ Block 3} \\
\hline $\begin{array}{l}\text { Total number of different } \\
\text { social activities done in last } \\
\text { month (out of listed 8) }\end{array}$ & $\begin{array}{l}0.843 \\
0.112\end{array}$ & $\begin{array}{l}0.335 \text { to } 1.351 \\
(3.259) \\
0.001\end{array}$ & $\begin{array}{l}-0.401 \\
-0.051\end{array}$ & $\begin{array}{l}-1.012 \text { to } 0.211 \\
(-1.288) \\
0.198 \mathrm{NS}\end{array}$ \\
\hline $\begin{array}{l}\text { Total number of relatives, } \\
\text { friends, neighbours who } \\
\text { would help with practical } \\
\text { tasks }\end{array}$ & $\begin{array}{l}0.106 \\
0.080\end{array}$ & $\begin{array}{l}0.035 \text { to } 0.177 \\
(2.949) \\
0.003\end{array}$ & $\begin{array}{l}-0.008 \\
-0.005\end{array}$ & $\begin{array}{l}-0.136 \text { to } 0.120 \\
(-0.125) \\
0.900 \mathrm{NS}\end{array}$ \\
\hline \multicolumn{5}{|l|}{ Block 4} \\
\hline $\begin{array}{l}\text { Self-rated health status, } \\
\text { compared to others of same } \\
\text { age }\end{array}$ & $\begin{array}{l}-1.289 \\
-0.100\end{array}$ & $\begin{array}{l}-2.298 \text { to }-0.279 \\
(-2.507) \\
0.012\end{array}$ & $\begin{array}{l}-2.443 \\
-2.228\end{array}$ & $\begin{array}{l}-3.445 \text { to }-1.441 \\
(-4.792) \\
0.0001\end{array}$ \\
\hline $\begin{array}{l}\text { ADL total score (sum of } \\
\text { ability to: walk } 400 \text { yards, do } \\
\text { heavy housework, shop/carry } \\
\text { heavy bags, steps/stairs) }\end{array}$ & $\begin{array}{l}-0.009 \\
-0.003\end{array}$ & $\begin{array}{l}-0.279 \text { to } 0.260 \\
(-0.069) \\
0.945 \mathrm{~ns}\end{array}$ & $\begin{array}{l}0.001 \\
0.001\end{array}$ & $\begin{array}{l}-0.276 \text { to } 0.278 \\
(0.007) \\
0.994 \text { NS }\end{array}$ \\
\hline \multicolumn{5}{|l|}{ Block 5} \\
\hline Age & $\begin{array}{l}0.044 \\
0.022\end{array}$ & $\begin{array}{l}-0.073 \text { to } 0.162 \\
(0.742) \\
0.458 \text { NS }\end{array}$ & $\begin{array}{l}-0.209 \\
-0.071\end{array}$ & $\begin{array}{l}-0.428 \text { to } 0.011 \\
(-1.867) \\
0.063 \mathrm{NS}\end{array}$ \\
\hline Sex & $\begin{array}{l}0.612 \\
0.021\end{array}$ & $\begin{array}{l}-0.914 \text { to } 2.139 \\
(0.788) \\
0.431 \mathrm{NS}\end{array}$ & $\begin{array}{l}0.055 \\
0.003\end{array}$ & $\begin{array}{l}-1.575 \text { to } 1.686 \\
(0.067) \\
0.947 \mathrm{NS}\end{array}$ \\
\hline Marital status & $\begin{array}{l}-0.341 \\
-0.027\end{array}$ & $\begin{array}{l}-1.046 \text { to } 0.364 \\
(-0.950) \\
0.342 \mathrm{NS}\end{array}$ & $\begin{array}{l}0.182 \\
0.014\end{array}$ & $\begin{array}{l}-0.817 \text { to } 1.181 \\
(0.358) \\
0.721 \mathrm{NS}\end{array}$ \\
\hline Housing tenure & $\begin{array}{l}-0.286 \\
-0.020\end{array}$ & $\begin{array}{l}-1.060 \text { to } 0.488 \\
(-0.726) \\
0.468 \mathrm{NS}\end{array}$ & $\begin{array}{l}-0.632 \\
-0.069\end{array}$ & $\begin{array}{l}-1.326 \text { to } 0.061 \\
(-1.793) \\
0.074 \mathrm{NS}\end{array}$ \\
\hline Constant & 159.694 & & 176.681 & \\
\hline $\mathrm{R} 2$ & 0.663 & & 0.453 & \\
\hline Adjusted R2 & 0.653 & & 0.430 & \\
\hline Anova F statistic; $p$ & $62.853 ; 0.0001$ & & $19.814 ; 0.001$ & \\
\hline
\end{tabular}

ADL, activities of daily living; NS, not significant; $00 L$, Quality of Life.

In support of construct (convergent) validity, the OPOOL correlated moderately strongly in the same direction, as hypothesised, ${ }^{7}$ with self-rated health status ('compared with others of same age') in each sample: OPQOL Ethnibus -0.364 ,
ONS -0.543 and QoL follow-up -0.628 . The CASP-19 and WHOQOL-OLD correlations in the two cross-sectional samples were also in the same direction and significant, although slightly weaker (CASP-19 Ethnibus -0.238, ONS -0.530; WHOQOL- 
OLD Ethnibus -0.138 , ONS -0.465 ; all $\mathrm{p}<0.01$ ). (Minus signs simply reflect different directions of coding).

\section{Multivariable analyses}

Multivariable analyses were conducted with each sample in order to examine independent predictors of the OPQOL, CASP19 and WHOQOL-OLD. For comparability, the same independent variables were entered into each model. On the basis of the literature, ${ }^{7}$ optimum scores on each measure were hypothesised to be associated with optimum QoL: self-rated active ageing, independent self-ratings of QoL domains, social activities and help from social network members, self-rated health status and physical functioning $(\mathrm{ADL})$, age, sex, marital status and housing tenure. The QoL follow-up sample also provided an opportunity to test the causal model underpinning the OPQOL.

\section{OPQOL}

The cross-sectional model for the QoL follow-up sample was highly significant (see table 1). Perceptions of ageing more actively, having optimal self-ratings of health, independence, home and neighbourhood, psychological well-being and finances, more social activities and female sex significantly, and independently, predicted optimal OPOOL scores. The amount of explained variance of OPOOL scores in the model was high at $77 \%$ (adjusted $\mathrm{R}^{2}$ 0.774).

The OPQOL models in the ONS and Ethnibus samples were also highly significant. Again, optimal ratings of active ageing, most self-rated QoL domains and also self-rated health status were significant in both samples. The model explained $65 \%$ of the variance in OPQOL scores (adjusted $\mathrm{R}^{2} 0.653$ ) in the ONS sample and $43 \%$ (adjusted $R^{2} 0.430$ ) in the Ethnibus sample (table 2).

The variables included in the test of the causal model underpinning the OPQOL, in the OoL follow-up sample, were the baseline indicators that reflected the components chosen for the OPOOL domains (health and functional status, practical help received, social support and activities, perceived quality of neighbourhood, psychological outlook, GAP score for social comparisons and expectations and self-efficacy), plus standard sociodemographic indications to control for their effects.

This model explained $56 \%$ of the variance in OPQOL scores (adjusted $\mathrm{R}^{2}: 0.563$ ). As number of different social activities was not significant in the model, a reduced model was conducted excluding this variable. Health status and number of diagnosed medical conditions, help and social support, perceptions of neighbourhood and feeling safe, social comparisons (comparing one's financial and living circumstances with others who are worse off), feelings of self-efficacy and control, then explained $48 \%$ of the variance in OPOOL scores in expected directions (adjusted $\mathrm{R}^{2}$ 0.481). The overall model was highly significant in general support of the OPOOL (see table 3).

\section{CASP-19}

The CASP-19 was assessed in the two ONS and Ethnibus samples. The amount of explained variance in CASP-19 scores in the ONS sample explained by the model was $57 \%$ (adjusted $\mathrm{R}^{2}$ 0.568); the model was highly significant, and in expected directions. The variables that retained significance in the model were five of the domain ratings, health and functioning. In contrast, the CASP-19 model for the Ethnibus sample was weak: the amount of explained variance in CASP-19 scores was just 14\% (adjusted $\mathrm{R}^{2} 0.141$ ), although the model was still significant. The variables that were significant were self-rated active ageing, and three of the seven QoL domain self-ratings, health status, but not physical functioning (see table 4).
Table 3 Causal model underpinning OPQOL

\begin{tabular}{|c|c|c|}
\hline Independent predictor variables & $\begin{array}{l}\text { Unstandardised } \\
\text { B } \\
\text { Standardised } \beta\end{array}$ & $\begin{array}{l}95 \% \text { CI (Two-tailed } \\
\text { t test) } \\
\text { p Value }\end{array}$ \\
\hline \multicolumn{3}{|l|}{ Final model 5} \\
\hline \multicolumn{3}{|l|}{ Block 1} \\
\hline $\begin{array}{l}\text { Self-rated health compared } \\
\text { with others of same age }\end{array}$ & $\begin{array}{l}-4.220 \\
-0.318\end{array}$ & $\begin{array}{l}-5.643 \text { to }-2.798 \\
(-5.846) \\
0.0001\end{array}$ \\
\hline No. of diagnosed medical conditions & $\begin{array}{l}-1.710 \\
-0.136\end{array}$ & $\begin{array}{l}-3.016 \text { to }-0.404 \\
(-2.579) \\
0.011\end{array}$ \\
\hline \multicolumn{3}{|l|}{ Block 2} \\
\hline $\begin{array}{l}\text { No. of five listed areas can } \\
\text { call for help and support with }\end{array}$ & $\begin{array}{l}6.368 \\
0.132\end{array}$ & $\begin{array}{l}1.837 \text { to } 10.900 \\
(2.769) \\
0.006\end{array}$ \\
\hline $\begin{array}{l}\text { Married/cohabiting versus single, } \\
\text { widowed, divorced }\end{array}$ & $\begin{array}{l}-2.811 \\
-0.097\end{array}$ & $\begin{array}{l}-5.724 \text { to } 0.103 \\
(-1.901) \\
0.059 \text { NS }\end{array}$ \\
\hline \multicolumn{3}{|l|}{ Block 3} \\
\hline $\begin{array}{l}\text { Self-rating of neighbourhood score } \\
\text { (quality, problems) }\end{array}$ & $\begin{array}{l}-3.176 \\
-0.199\end{array}$ & $\begin{array}{l}-4.665 \text { to }-1.688 \\
(-4.205) \\
0.0001\end{array}$ \\
\hline $\begin{array}{l}\text { Feels safe walking alone day } \pm \text { night } \\
\text { score }\end{array}$ & $\begin{array}{l}3.850 \\
0.099\end{array}$ & $\begin{array}{l}0.268 \text { to } 7.433 \\
(2.118) \\
0.035\end{array}$ \\
\hline \multicolumn{3}{|l|}{ Block 4} \\
\hline $\begin{array}{l}\text { GAP score: social comparisons worse, } \\
\text { same or better off than others }\end{array}$ & $\begin{array}{l}-7.440 \\
-0.227\end{array}$ & $\begin{array}{l}-10.504 \text { to }-4.376 \\
(-4.784) \\
0.0001\end{array}$ \\
\hline Self-efficacy score & $\begin{array}{l}-2.145 \\
-0.155\end{array}$ & $\begin{array}{l}-3.461 \text { to }-0.829 \\
(-3.211) \\
0.002\end{array}$ \\
\hline \multicolumn{3}{|l|}{ Block 5} \\
\hline Age & $\begin{array}{l}-0.486 \\
-0.221\end{array}$ & $\begin{array}{l}-0.698 \text { to }-0.274 \\
(-4.510) \\
0.001\end{array}$ \\
\hline Sex & $\begin{array}{l}3.077 \\
0.109\end{array}$ & $\begin{array}{l}0.402 \text { to } 5.751 \\
(2.267) \\
0.024\end{array}$ \\
\hline $\begin{array}{l}\text { Housing tenure: home-owner/mortgage } \\
\text { versus rent/other }\end{array}$ & $\begin{array}{l}1.149 \\
0.035\end{array}$ & $\begin{array}{l}-1.999 \text { to } 4.297 \\
(0.719) \\
0.473 \text { NS }\end{array}$ \\
\hline Constant & 175.666 & \\
\hline $\mathrm{R}^{2}$ & 0.505 & \\
\hline Adjusted $\mathrm{R}^{2}$ & 0.481 & \\
\hline Anova F statistic; $p$ value & $21.629 ; 0.0001$ & \\
\hline
\end{tabular}

$\mathrm{ADL}$, activities of daily living; NS, not statistically significant at least the 0.05 level; OPOOL, Older People's Quality of Life.

Multiple regression of baseline (1999/2000) predictors of OPOOL at follow-up (2007/2008): OoL follow-up sample (final model).

\section{WHOOOL-OLD}

The WHOQOL-OLD was assessed in the ONS and Ethnibus samples The amount of explained variance in WHOQOL-OLD scores in the ONS Omnibus survey was $45 \%$ (adjusted $\mathrm{R}^{2}$ 0.448); the model was highly significant, again in expected directions. The significant variables were self-rated active ageing, three of the seven QoL domain ratings and the number of social activities and helpers, health status and housing tenure. However, the WHOQOL-OLD model for the Ethnibus sample was weak, although significant: the amount of explained variance in WHOQOL-OLD scores was just $5 \%$ (adjusted $\mathrm{R}^{2}$ 0.048). The significant variables were three of the seven domain ratings, and number of social activities (see table 5).

\section{CONCLUSION}

This study describes the psychometric performance of a QoL questionnaire, developed from the perspectives of older people 
Table 4 Multiple regression of predictors of CASP-19:ONS OMNIBUS and Ethnibus (final models)

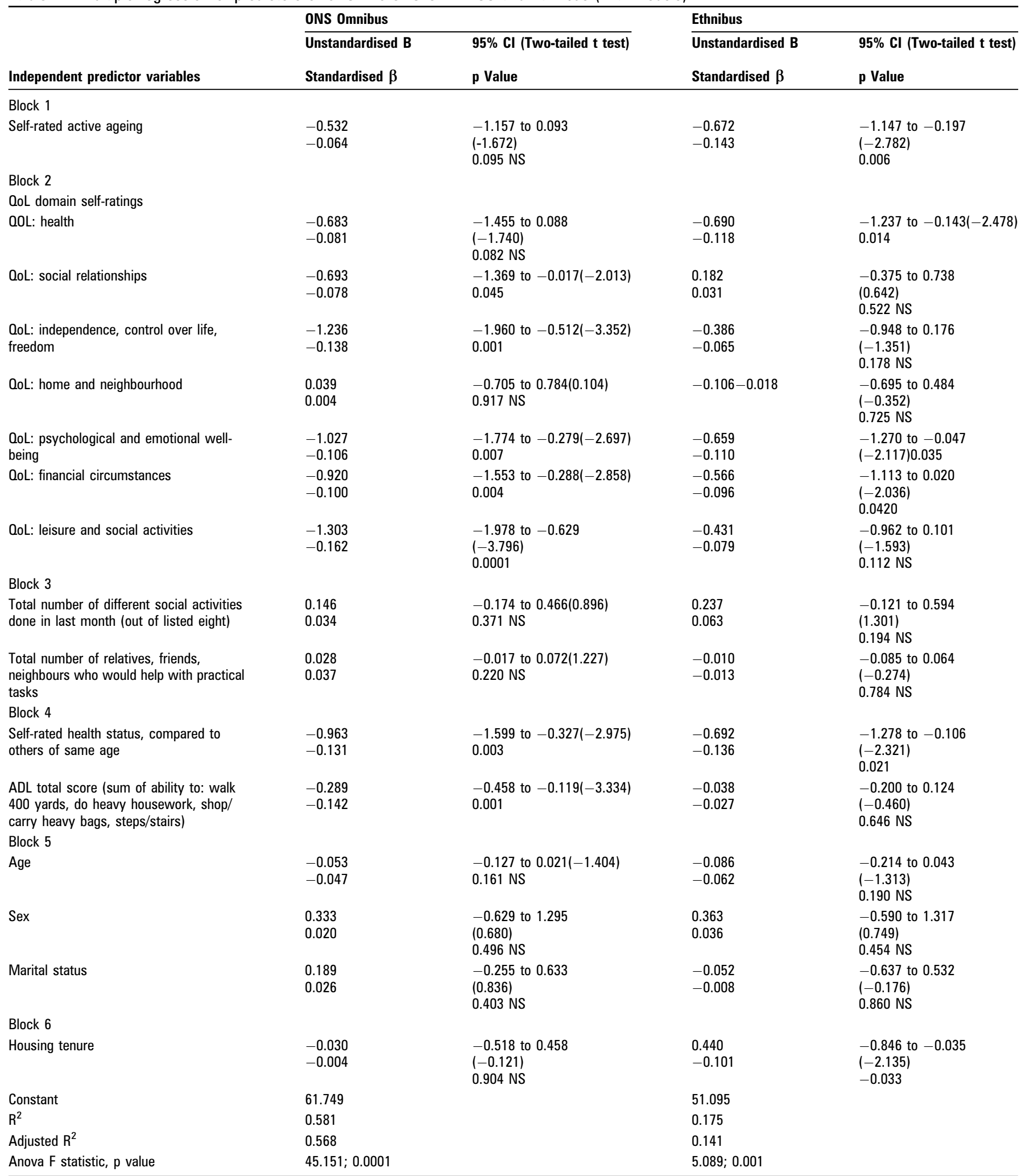

ADL, activities of daily living; NS, not significant; $00 L$, Quality of Life.

themselves: the OPQOL. It was tested in two cross-sectional, and one longitudinal, surveys of older people across Britain. The longitudinal survey enabled the OPQOL to be tested in a dynamic, ageing population and an assessment of its underlying model, although its self-administration mode necessitated the assessment of the OPQOL only (and not the CASP-19 or WHOQOL) in this older sample.

The surveys used statistically robust sampling methods, and the response rates were fairly to very good. The characteristics of respondents to the ONS Omnibus and Ethnibus surveys (and 
Table 5 Multiple regression of predictors of WHOOOL-OLD: ONS OMNIBUS and Ethnibus (final model)

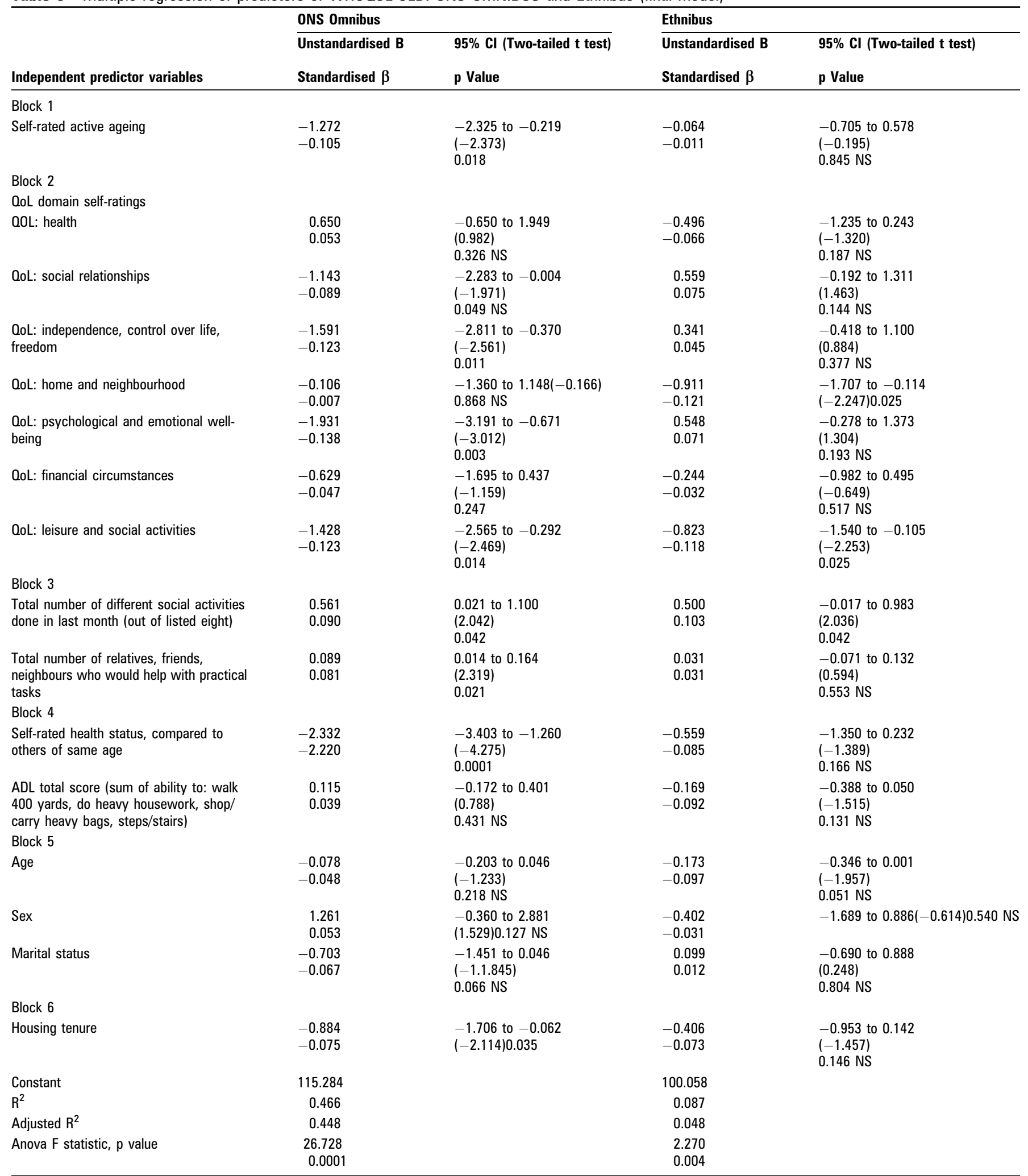

ADL, activities of daily living; NS, not significant; 00L, Quality of Life.

the QoL survey at baseline) were comparable with population estimates from the last census. However, non-response is still a cause for concern. The QoL follow-up sample, by its longitudinal design, reflected the healthy survivors. Also, although the sampling approach of the Ethnibus survey was statistically robust, it used focused enumeration. There is no other practical methodology for attempting to obtain representative samples of people in ethnic minority groups in national samples.

This study reported that Ethnibus respondents obtained poorer (worse) QOL scores than the other sample respondents, with the OPQOL, CASP-19 and WHOQOL-OLD. This is not unexpected given that people in ethnic minority groups are often more 


\section{What is already known on this subject}

- Increasing numbers of older people, higher expectations for 'a good life', and demands for health and social care, have led to international interest in the enhancement, and measurement, of quality of life $(\mathrm{OoL})$ in older age.

- $\mathrm{OoL}$ is a subjective concept, yet most measures of $\mathrm{OoL}$ are based primarily or partly on 'expert' opinions.

\section{What this study adds}

- This study focuses on the testing of a new measure of $\mathrm{OoL}$, the Older People's QoL Questionnaire (OPOOL), which was derived entirely from the views of older people in Britain, cross-checked against theoretical models for comprehensiveness.

- The OPQOL performed well in three samples of older people in Britain, one of which comprised people from ethnic minority groups. It is of potential value in the outcome assessment of health and social interventions, which can have a multidimensional impact on people's lives.

economically disadvantaged than the wider population. ${ }^{15}$ Further research is needed to examine whether differences in QoL reflect real variations, methodology, and cultural variations in expectations or in reporting. Ethnic minority groups in Britain live in a wide range of different communities, and their diversity may also have affected responses in some way. Hence, variations in QoL by ethnic group requires caution in interpretation. It should also be noted that the standard question for ethnic status used, largely reflected Britain's New Commonwealth groups, and may not be appropriate for use in other countries.

The OPQOL performed well in psychometric tests of reliability and validity. Multiple regression models supported its validity and underlying constructs.

Despite the Ethnibus sample's consistently worse QoL scores, compared with the other samples, the CASP-19 and WHOQOLOLD did not meet all criteria for internal consistency (reliability) in the ethnically diverse Ethnibus sample. The CASP-19 and WHOQOL-OLD also had relatively large numbers of items that failed to meet the reliability criterion for item-total scale correlations; they frequently failed correlation tests for validity in the Ethnibus sample. This may have been due to this sample's ethnic diversity, or because the CASP-19 and WHOQOL-OLD were not sufficiently sensitive.

Health and social care interventions can have a multifaceted impact on people's lives. The OPQOL is of potential value in descriptive and evaluative research. This research supports the use of the OPQOL in older populations in Britain. It awaits testing in other countries, and with different ethnic minority population groups. The OPQOL is currently being tested with older people living in Italy; initial results for cultural equivalence and understanding are positive (personal communication, Dr Claudio Bilotta, University of Milan).

Acknowledgements Thanks are due to ONS Omnibus Survey and Ethnibus staff for mounting the Quality of Life and Active Ageing modules, and processing the data. Material from the ONS Omnibus Survey, made available through ONS, has been used with the permission of the Controller of The Stationery Office. I also thank Professor Steve lliffe, Ms Kalpa Karachi, and Ethnifocus for organising focus groups to comment on the OPOOL questionnaire, members of the study advisory group, and Ms Corinne Ward for her administration of the OoL follow-up survey and data processing. Members of ONS Omnibus and Ethnibus who carried out the original analysis and collection of the data hold no responsibility for the further analysis and interpretation of them.

Funding The study was funded by the UK cross-research council New Dynamics of Ageing Programme; we are grateful for their support: New Dynamics of Ageing Research Programme; grant reference number: RES-352-25-0001. The sponsors played no role in the design, execution, analysis, interpretation and writing of the study.

\section{Competing interests None.}

Ethics approval This study was conducted with the approval of the University College London Research Ethics Committee.

Contributors $A B$ was PI of the grant, managed the study, conducted the statistics and wrote the first and final draft of this paper in collaboration with PS, coapplicant and coauthor.

Provenance and peer review Not commissioned; externally peer reviewed.

\section{REFERENCES}

1. World Health Organization. Active ageing. A policy framework. Geneva: WHO, 2002. http://www.who.int/hpr/ageing/ActiveAgeingPolicyFrame.pdf (accessed Apr 2010).

2. Lawton MP. Competence, environmental press and adaptation of older people. In: Lawton MP, Windley PG, Byerts TO, eds. Aging and environment. Theoretical approaches. New York: Springer, 1982:33-59.

3. Lawton MP. Environment and other determinants of well-being in older people. Gerontologist 1983;23:349-57.

4. Lawton MP. The varieties of well-being. Exp Aging Res 1983;9:65-72.

5. Lawton MP. Background. A multidimensional view of quality of life in frail elders. In: Birren JE, Lubben J, Rowe J, et al, eds. The concept and measurement of quality of life in the frail elderly. San Diego: Academic Press, 1991:4-27.

6. Lawton MP. Quality of life and affect in later life. In: Magai C, McFadden SH, eds Handbook of emotion, human development, and aging. San Diego: CA Academic Press, 1996. 327-48

7. Bowling A. Ageing well. Quality of life in old age. Maidenhead: Open University Press, 2005.

8. Bowling A, Bannister D, Sutton $S$, et al. A multidimensional model of $\mathrm{QoL}$ in older age. Ageing Ment Health 2002;6:355-71.

9. Bowling A, Gabriel Z. An integrational model of quality of life in older age. A comparison of analytic and lay models of quality of life. Soc Indic Res 2004;69:1-36

10. Gabriel Z, Bowling A. Perspectives on quality of life in older age: older people talking. Ageing Soc 2004;24:675-91.

11. Hyde $\mathbf{M}$, Wiggins RD, Higgs $P$, et al. A measure of quality of life in early old age: the theory, development and properties of a needs satisfaction model (CASP-19). Ageing Ment Health 2003; 7:186-94.

12. Power M, Harper A, Bullinger M. the WHO Quality of Life Group. The World health Organisation WHOOOL-100: tests of the universality of quality of life in 15 different cultural groups worldwide. Health Psychol 1999;18:495-505.

13. Power M, Quinn K, Schmidt S, WHOQOL-OLD Group. Development of WHOOOLOLD module. Qual Life Res 2005;14:2197-214.

14. Hagerty MR, Cummins RA, Ferriss AL, et al. Quality of life indexes for national policy: review and agenda for research. Soc Indic Res 2001;55:1096.

15. Nazroo J, Bajekal M, Blane D, et al. Ethnic inequalities. In:Walker A, Hennesy CH eds. Growing older. Quality of life in old age. Maidenhead: Open University Press, 2004:35-59. 